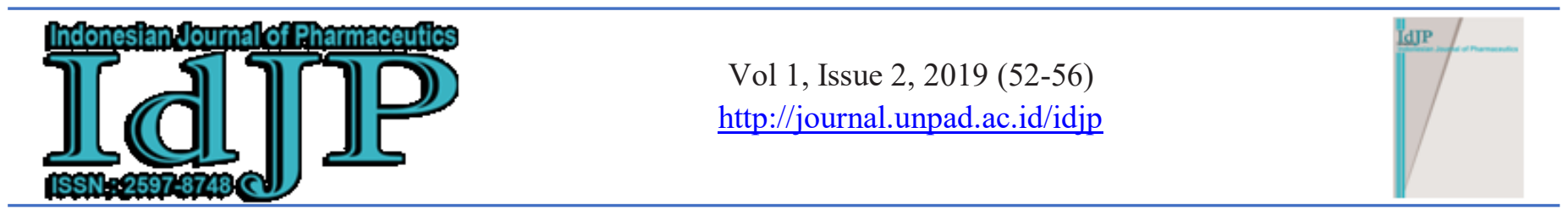

\title{
The Effect of Citronella Oil Concentration (Cymbopogon nardus (L. ) Rendle) on the Quality of Shampoo and Antifungal Activity of Candida albican
}

\author{
Lidya Ameliana*, Alik Almawadah, Lestyo Wulandari \\ Departement of Pharmaceutics and Pharmaceutical Technology, Faculty of Pharmacy, University of \\ Jember, Jember, Indonesia
}

Received: 17 May 2019/Revised: 20 May 2019/Acepted: 27 May 2019/Published: 13 Jun 2019

\begin{abstract}
Citronella oil (Cymbopogon nardus (L.) Rendle) is formulated into shampoo preparations to overcome dandruff. Dandruff is a condition which exfoliation of the excess horny layer on the scalp and forms fine scales caused by fungal infections of Candida albicans. The purpose of this study was to determine the antifungal activity and quality of the citronella oil shampoo. Citronella oil was taken using a steam distillation method. The oil produced has good quality because it meet the range of organoleptic requirements according to EOA, 1975, the refractive index 1.483-1.489), density $(0.800-0.900 \mathrm{~g} / \mathrm{mL})$, and the minimum concentration of citronella content is $35 \%$. In this research obtained that the refractive index 1.483 , density $0.890 \mathrm{~g} / \mathrm{mL}$ and citronellal content $41.720 \%$. The shampoo was formulated to $1 \%$, $2 \%, 3 \%, 4 \%$ and $5 \%$ of citronella oil concentration to MIC (Minimum Inhibition Concentration) test, to find out the lowest concentration of shampoo which can still inhibit the growth of Candida albicans and the MIC was $2 \%$. Citronella oil then formulated into shampoo with F1 (4\%) F2 (6\%) and F3 $(8 \%)$ citronella oil concentrations. The results of the quality of shampoo evaluation showed that all formulations met the requirements of $\mathrm{pH}$, viscosity, and foam height. In testing the antifungal activity of shampoo was known that the greater the concentration of oil in the shampoo, the greater the antifungal activity in the shampoo.
\end{abstract}

Keywords: Citronella oil, shampoo, antifungal activity

\section{Introduction}

In this time, dandruff is still a major problem in almost all individuals. The onset of dandruff observed in the presence of white scales, itching that occurs on the scalp and hair loss [1]. According to Harahap (1990), the secretion of excessive sweat glands and the emergence of microorganisms on the scalp can also trigger the formation of dandruff. The most common causes of dandruff are Candida albicans with a percentage of $50 \%$ followed by $24 \%$ Aspergillus niger, 16\% Cryptococcus spp and 10\% Penicillium spp. It was proven by a study conducted by Roselin (2015) on dandruff samples taken from 50 volunteers with ages ranging from 18 years to 25 years and it was known that Candida albicans is the main that causes dandruff. [3-4]

Dandruff can be treated with several anti-dandruff substances including zinc, menthol, and thymol. However, the use of these chemicals can cause hair loss and some adverse skin reactions, such as rashes, pruritus, and dermatitis. To overcome this, some natural agents such as citronella oil is good. Citronellal oil (Cymbopogon nardus (L.) Rendle) has several chemical constituents including citronellal, citronellol, geraniol which have antifungal and antibacterial activity [4]. Citronella oil has antifungal activity against several Candida species namely
Candida albicans, Candida glabrata, Candida krusei, Candida parapsilosis and Candida tropicalis [5]. According to the Lely, 2018 citronella oil (Cymbopogon nardus (L.) Rendle) has antifungal activity on three types of microorganisms namely Trichophyton rubrum, Trichophyton mentagrophytes and Candida albicans, the largest inhibitory zone was found in Candida albicans. The aplication of citronella oil directly on the skin is considered to be less practical and effective. So, it needs to formulate topical preparations used an antifungal for Candida albicans. Topical preparations that are suitable for fighting dandruff are anti-dandruff shampoo. The shampoo is a liquid, gel, emulsion, or aerosol preparation that contains surfactants so that it can produce foam. The quality requirements of shampoo preparations which are determined according to the Indonesian National Standard (SNI) are $\mathrm{pH}$ of 5.09.0 SNI No. 06-2692-1992. While the viscosity of the shampoo is between $4-40 \mathrm{dPas}$ [8]. And high foam shampoo is $1.3-22 \mathrm{~cm}$ [9]. The objective of this research was to formulated of citronella oil into anti-dandruff shampoo preparations as well as an antifungal activity test against Candida albicans.

\section{Method}

2.1 Tools

*Corresponding author, e-mail : lidyaameliana@unej.ac.id (L.Ameliana) 
The tools used in this research are Steam distillation apparatus, analytic balance (AdventureTM Ohaus, USA), viscometer (Rion Viscotester VT-04), Oven, $\mathrm{pH}$ meter (Elmetron), refractometer, petri dish, porcelain saucer, mortar, stamper, glassware (Pyrex) and SPSS data processing software.

\subsection{Materials}

The materials used in this research were citronella plants (collected from Botanical Garden in Agrotechnopark, University of Jember, Jubung, Jember) and determination of citronella plant was carried out in the Plants Laboratory ,Politeknik Negeri Jember. Chemical reagents were hydroxylamine hydrochloride (Loba Chemie), $\mathrm{KOH}, \mathrm{HCl}$, ethanol, sodium lauryl sulfate (Brataco), carbopol (Inalab), TEA (Brataco), methylparaben (Brataco), propylparaben (Brataco), distilled water, culture

C. albicans obtained from the Faculty of Dentistry, University of Jember, and Soboraud Dextrose Agar (SDA).

\subsection{Preparation of Sample}

\subsubsection{Isolation of Citronella oil}

Isolation of citronella oil was carried out by direct steam distillation. The oil produced from the distillation process calculated using the following formula:

$\%$ Yield $=\frac{\text { Volume citronella oil }(\mathrm{mL})}{\text { Weight of simplicia }(\mathrm{g})} \times 100$

\subsection{Evaluation of Citronella Oil Quality}

The evaluation was carried out to determine quality of citronella oil produced in this research, then compare with the quality of citronella oil sample (citronella oil on the Jember local market). The evaluation included organoleptic, refractive index, and density of the citronella oil.

The organoleptic test includes color and odor. In general, citronella oil has a pale yellow to brownish yellow color, with a distinctive smell of citronella. Refractive index test was using refractometer, citronella oil has a refractive index of 1.483-1.489 at $20^{\circ} \mathrm{C}[10]$. And the density test was using pycnometer, citronella oil at a temperature of $25^{\circ} \mathrm{C}$ has specific gravity $0.800-0.900 \mathrm{~g} / \mathrm{mL}[10]$.

\subsubsection{Citronella content}

Citronella oil content was carried out by weighing 0.8 grams of citronella oil into erlenmeyer, adding $20 \mathrm{~mL}$ of hydroxylamine hydrochloride $0.5 \mathrm{~N}$ and $10 \mathrm{~mL}$ of $\mathrm{KOH} 0.5 \mathrm{~N}$. Then the bromophenol blue indicator was added and titration using $0.5 \mathrm{~N} \mathrm{HCl}$ until the color changes from blue to yellow. Then make a blank [11].

$\%$ Percent Citronellal $=\frac{M(V 1-V 0)}{20 \mathrm{~m}} \times f k$

M: BM citronellal

$\mathrm{m}$ : The mass of citronella oil

V0: Volume of $0,5 \mathrm{~N} \mathrm{HCl}$ determination

V1: Volume of $0,5 \mathrm{~N}$ blank $\mathrm{HCl}$

FK : 0,889

\subsection{Determination of Minimum Inhibitory Concentration (MIC)}

MIC was carried out on several citronella oil shampoos with concentrations $1 \%, 2 \%, 3 \%, 4 \%$ and $5 \%$, and using the well diffusion method. SDA (Saburound Dextrose Agar) is the media used in MIC testing. 6.5 grams of SDA were suspended in $100 \mathrm{~mL}$ distilled water put into erlenmeyer, warmed to homogeneous then closed the erlenmeyer using cotton and sterilized. Liquid SDA was poured into a petri dish waiting until it solidified. The suspension of Candida albicans was made with took one ose of Candida albicans then put in a mixed of physiological $\mathrm{NaCl}$ and vortex the mixture. $100 \mu 1$ of Candida albicans suspension spreaded above SDA. Then pipette the test solution for $20 \mu 1$ and put in the hole. The antifungal activity can be found based on the presence of inhibition diameter that appears around the well hole. The smallest concentration that produces an inhibitory diameter was determined as MIC.

\subsection{Formulation of Citronella Oil Shampoo}

The shampoo was made in several formulas shown in Table 1. The following steps to get a shampoo: developing carbopol in the mortar using distilled water until it expands, stirring constantly and adding a TEA until homogeneous. Nipagin and nipasol dissolved using propylene glycol, while sodium lauryl sulfate was dissolved using distilled water. The mixture of nipagin and nipasol added into the mortar containing the carbopol then adding sodium lauryl sulfate, stirred slowly. Added the citronella oil and the remaining of distilled water was added to the mixture and stirred until homogeneous. The following formulations of citronella oil shampoo are presented in Table 1.

\subsection{Evaluation of Citronella Oil Shampoo}

The evaluation of citronella oil shampoo were include, organoleptic, $\mathrm{pH}$, viscosity and foam height test. Organoleptic evaluation was carried out visually which included shape, color, and odor. Evaluation of $\mathrm{pH}$ was perform by dissolved 1 gram of shampoo in $10 \mathrm{ml}$ of distilled water. According to SNI 062692-1992, pH shampoo is ranging from 5.0 to 9.0. The viscosity of shampoo according to Schmitt and 
Table 1. Formulation of citronella oil shampoo

\begin{tabular}{cccccc}
\hline \multirow{2}{*}{ Materials } & Function & \multicolumn{4}{c}{ Concentration $(\% \mathrm{~b} / \mathrm{b})$} \\
\cline { 3 - 6 } & & F0 & F1 & F2 & F3 \\
\hline Citronella oil & Active Ingredients & 0 & 4 & 6 & 8 \\
Carbopol & Thickening Agent & 1 & 1 & 1 & 1 \\
Sodium Lauryl Sulfate & Foaming Agent and Emulgator & 3,5 & 3,5 & 3,5 & 3,5 \\
Propylene Glycol & Cosolvenic & 10 & 10 & 10 & 10 \\
Nipagin & Preservative & 0,02 & 0,02 & 0,02 & 0,02 \\
Nipasol & Preservative & 0,01 & 0,01 & 0,01 & 0,01 \\
Triethanolamine (TEA) & Alkalizing Agent & 2 & 2 & 2 & 2 \\
Aquadest & Solvent & 83,47 & 79,47 & 77,47 & 75 \\
Total & & $100 \mathrm{~g}$ & $100 \mathrm{~g}$ & $100 \mathrm{~g}$ & $100 \mathrm{~g}$ \\
\hline
\end{tabular}

Williams (1996) ranges from $4 \mathrm{dPas}-40 \mathrm{dPas}$. The test was evaluated using viscometer (Rion Viscometer VT-04). Evaluation of foam height was obtained by dissolved 0.1 gram shampoo in $10 \mathrm{~mL}$ of distilled water and put the solution into a test tube then closed tightly then shaked for 20 seconds, and measured the foam [12]. The requirements for high foam shampoo are $1.3-22 \mathrm{~cm} \mathrm{[9].}$

\subsection{Antifungal Activity Test}

Antifungal activity tests were carried out by the same method in the MIC test. The test solution consisted of the negative control (F0), positive control (ketoconazole shampoo) and citronella oil shampoo F1 (4\%), F2 (6\%) and F3 (8\%). Incubated for 48 hours at $37^{\circ} \mathrm{C}$. And calculated the diameter inhibition using calipers [4].

\section{Result}

\subsection{Isolation of citronella oil}

The citronella plant was found that is Cymbopogon nardus (L.) Rendle and the family are Poaceae. Yield of the citronella oil was $0.857 \%$. The yield of oil is $0.28 \%-1.4 \%$, according to the Negrelle and Gomes ,2007. According to Ginting ,2004 the yield of oil obtained from citronella plants depends on several factors including the existence of differences in climate, soil fertility, age of plants and isolation of citronella oil.

\subsection{Evaluation of Citronella Oil}

The organoleptic test of citronella oil was found that citronella oil and citronella oil sample have a yellow color with a distinctive smell of lemongrass, the two types of oil meets the requirement of color range. The refractive index of citronella oil was 1.483 and 1.467 for the citronella oil sample ( citronella oil on the Jember local market). Refractive index of the citronella oil was meets the requirement, but the citronella oil sample does not. According to EOA,1975 the refractive index of citronella oil at temperature of $20^{\circ} \mathrm{C}$ is $1.483-1.489$. The density of citronella oil was $0.890 \mathrm{~g} / \mathrm{mL}$ and 0.881 for the citronella oil sample. According to EOA, 1975 the requirement of the density of oil at a temperature of $25^{\circ} \mathrm{C}$ is $0.8-0.9 \mathrm{~g} / \mathrm{mL}$. So, the two types of oil in the range of requirements.

\subsubsection{Citronella content}

Citronella oil has a citronella content that is in the range of requirements, but the citronella oil sample does not. Minimum citronellal content is 35\% [10]. The citronella content of citronella oil was $41.72 \%$ and $11.74 \%$ for the citronella oil sample.

\subsection{Evaluation of Citronella Oil Shampoo}

Organoleptic test of citronella oil shampoo F0 $(0 \%)$, F1 (4\%), F2 (6\%) and F3 (8\%) showed that the concentration of citronella oil could affect the shape, smell and color of the shampoo. The result can be seen in Table 2 and Picture 1.

Based on the results of the $\mathrm{pH}$ test the addition of citronella oil concentration caused a decrease in $\mathrm{pH}$. because citronella oil is acidic. In all formulation, the $\mathrm{pH}$ meets the range on the requirements of SNI No. 06-2629-1992 which ranges 5.0-9.0. The viscosity test showed that all shampoo formulas meet the viscosity range of requirement, according to Schmitt et all,1996 (4 dPas - $40 \mathrm{dPas})$. The viscosity of the shampoo decreases with increasing concentration of citronella oil. The foam height of shampoo in all formulas meets the requirement. According to Wilkinson, 1982 the foam height of shampoo is 1.3 $\mathrm{cm}-22 \mathrm{~cm}$. The test result can be seen in Table 3 .

\subsection{Determination of MIC}

The inhibition zone appears on the shampoo with a 
concentration of $2 \%, \mathrm{~F} 33 \%, 4 \%$, and $5 \%$. The MIC results of citronella oil shampoo against Candida albicans was on shampoo $2 \%$, because it was the smallest concentration which still inhibit Candida albicans. The results of the MIC test can be seen in
Table 4.

\subsection{Antifungal Activity Test}

The antifungal activity was characterized by the

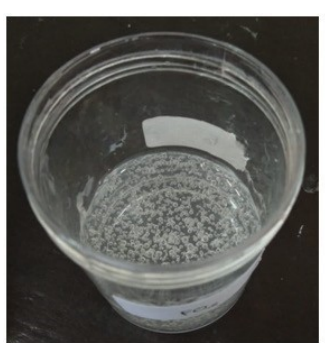

F0 $(0 \%)$

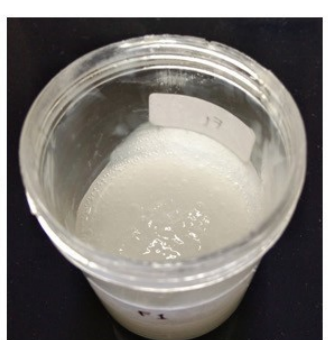

F1 (4\%)

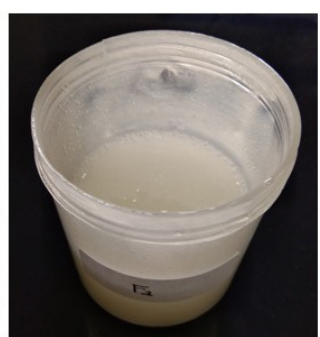

F2 (6\%)

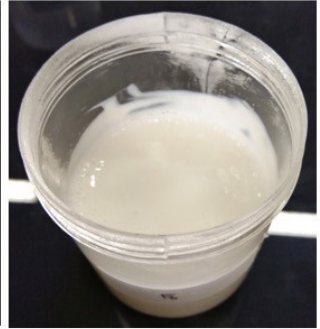

F3 $(8 \%)$

Picture 1. Shampoo all concentration

Table 2. Organoleptic test result

\begin{tabular}{cccc}
\hline Formula & Shape & Odor & Color \\
\hline 0 & Gel & None & None \\
1 & Emulgel & Aromatic & White \\
2 & Emulgel & Aromatic & White \\
3 & Emulgel & Aromatic & White \\
\hline
\end{tabular}

Table 3. Evaluation of citronella oil shampoo test result $(n=3)$

\begin{tabular}{cccc}
\hline Formula & $\mathrm{pH} \pm \mathrm{SD}$ & Viscosity $(\mathrm{dPas}) \pm \mathrm{SD}$ & Foam Height $\pm \mathrm{SD}$ \\
\hline 0 & $8.14 \pm 0.02$ & $32.67 \pm 0.58$ & $4.45 \pm 0.05$ \\
1 & $8.03 \pm 0.03$ & $24.00 \pm 1.00$ & $3.90 \pm 0.17$ \\
2 & $7.86 \pm 0.02$ & $17.67 \pm 1.53$ & $3.40 \pm 0.10$ \\
3 & $7.71 \pm 0.02$ & $6.00 \pm 0.00$ & $2.69 \pm 0.12$ \\
\hline
\end{tabular}

Table 4. MIC test result

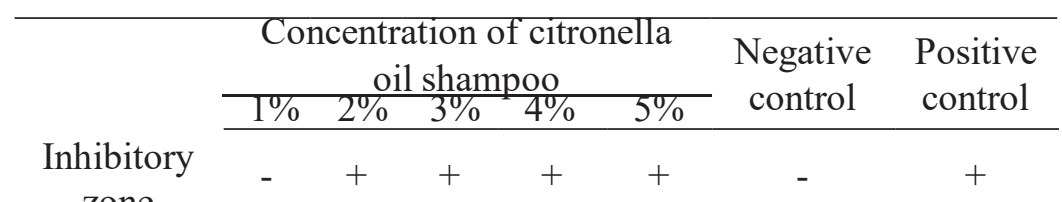

: There is no inhibition zone

$(+) \quad$ : There are inhibitory zones

Negative control : Base shampoo

Positive control : Ketoconazole shampoo

Table 5. Antifungal activity test result

\begin{tabular}{cc}
\hline Formula $(\mathrm{F})$ & Inhibitory zone $(\mathrm{mm}) \pm \mathrm{SD}$ \\
\hline 0 & $11.1 \pm 0.12$ \\
1 & $14.7 \pm 0.15$ \\
2 & $16.3 \pm 0.12$ \\
3 & $19.5 \pm 0.31$ \\
Positive control & $22.7 \pm 0.42$ \\
\hline
\end{tabular}


presence of inhibitory zones, then measured using the calipers and the results can be seen in Table 5 . The test showed that all formulas have an inhibitory zone against Candida albicans. The negative control shampoo also showed the presence of an inhibitory zone, but the inhibition zone was due to the availability of preservatives.

\section{Discussion}

The results were obtained that citronella oil in this study had good quality. Because in all tests including organoleptic, refractive index, density, and citronellal content of oil in the range of requirements. But the refractive index and citronellal content of the citronella oil sample (citronella oil on the market) did not meet the requirement in the literature, because the mixture of other oil in the citronella oil sample. Components contained in citronella oil can affect the results of refractive index measurements. The presence of water content in oil can decrease the refractive index [14].

The results of the physical evaluation of the shampoo showed that all tests including organoleptic, $\mathrm{pH}$, viscosity and foam height were included in the range of requirements. The oil in the shampoo can affect the shape, smell and color of the shampoo. F0 shampoo is a shampoo base without citronella oil, so obtained the gel shampoo. The absence of oil in the preparation produced a shampoo that was odorless and colorless. The large amount of oil on shampoo can cause the color intensity of the shampoo became more white and the odor produced more aromatic. The addition of the concentration of oil in the shampoo can reduce the $\mathrm{pH}$, viscosity, and the foam height of the shampoo. However, with the addition of citronella oil concentration increase the antifungal activity against Candida albicans. In all responses includes the quality of the shampoo and the antifungal activity, the statistical test was performed with Oneway ANOVA and showed significant differences in one experimental group with $\mathrm{p}<0.05$. Followed by the Least Significant Different (LSD) test obtained $\mathrm{p}$ $<0.05$ so that there were significant differences in all experimental groups.

\section{Conclusion}

In this study, citronella oil has good quality and meet the requirements of the refractive index, density and citronellal content of oil according to the literature. The MIC of citronella oil shampoo was $2 \%$. Increasing the concentration of citronella oil in the shampoo can reduce $\mathrm{pH}$, viscosity, and foam height of the shampoo. Increasing the concentration of citronella oil in shampoo can increase antifungal activity against Candida albicans.

\section{Acknowledgments}

Authors thanks to LP2M University of Jember for fundy this study by Hibah Penugasan UNEJ.

\section{References}

[1] Basheer, J., A. Sayeed, dan S. K. J. Shahina.2014. Isolation and Characterization Of The Fungi from Dandruff-Afflicted Human Scalp And Evaluation of Anti-Dandruff Shampoo. Indian Journal of Applied Research. 4(9):253-255.

[2] Harahap. 1990. Penyakit Kulit. Jakarta: PT. Gramedia

[3] Roselin, M. 2015. Fungal Infections in Dandruff Afflicted Scalps on Medical Students. International Journal of Current Research.

[4] Fitriani, E., M. Alwi, D. Umrah, ) Alumni, J. Biology, F. Matematika, I. Pengetahuan, A. Universitas, T. Kampus, B. Tadulako, T. Palu, S. Tengah, dan T. B. Tadulako. 2013. Studi Efektivitas Ekstrak Daun Sereh Wangi (Cymbopogon nardus L.) sebagai Anti Fungi Candida albicans. Jurnal Biocelebes. 7(2):1978-6417

[5] Silva, C. D. B. Da, S. S. Guterres, V. Weisheimer, dan E. E. S. Schapoval. 2008. Antifungal Activity of the Lemongrass Oil and Citral against Candida spp. The Brazilian Journal of Infectious Diseases. 12(1):63-66.

[6] Lely, N., H. Sulastri, dan S. Meisyayati. 2018. Aktivitas Antijamur Minyak Atsiri Sereh Wangi (Cymbopogon nardus (L.) Rendle). Jurnal Kesehatan Saelmakers Perdana. 1(1):31-37.

[7] SNI. 1992. Shampoo .

[8] Schmitt dan Williams 1996. Chemistry and Technology of The Cosmetics and Toiletries Industry. Edisi 2nd. London: Balkie Academic \& Professional an Imprint of Chapman and Hall.

[9] Wilkinson. 1982. Harry's Cosmeticology 7th Edition. London: George Godwin.

[10] EOA. 1975. Essential Oil Association of the U.S.A. New York: Essential Oil Association of U.S.A., Inc.

[11] Ginting, S. 2004. Pengaruh Lama Penyulingan Terhadap Rendemen Dan Mutu Minyak Atsiri Daun Sereh Wangi. E-USU Repository. 1-22.

[12] Sitompul, M. B., P. V. . YamLean, dan N. S. Kojong. 2016. Formulasi dan Uji Aktivitas Sediaan Sampo Antiketombe Ekstrak Etanol Daun Almanda (Allamanda cathartica L.) Terhadap Pertumbuhan Jamur Candida albicans Secara in Vitro. Pharmacon. 7(2):123-124

[13] Negrelle, R. R. B. dan E. C. Gomes. 2007. Cymbopogon citratus (dc.) stapf: chemical composition and biological activities. Revista Brasileira de Plantas Medicinais. 9(1):80-92

[14] Kataren dan Mulyono. 1990. Minyak Atsiri. Jakarta: Universitas Indonesia Press. 